\title{
LOS SILENCIOS DEL DAÑO EN LA POESÍA COLOMBIANA
}

\author{
OS SILENNCIOS DO DANO NA POESIA COLOMBIANA
}

\author{
Óscar Daniel Clavijo Tavera ${ }^{1}$
}

RESUMEN: A partir de algunos esfuerzos de desambiguación del silencio en relación con la experiencia del daño, este artículo analiza las maneras, temáticas y expresivas, en que la reciente poesía colombiana de la violencia asume el silencio como objeto de la reflexión poética. El texto inicia con un repaso alrededor de formulaciones teóricas que se han aproximado, desde la sociología y la filosofía política, a clasificar las posibilidades de significación del silencio en su dimensión política, estrechamente relacionada con las prácticas y los discursos de la violencia en Colombia. Posteriormente, emprende el análisis de los campos semánticos y de las estructuras sintácticas y de enunciación de un grupo de poemas con el fin de establecer las formas en que dicho silencio ingresa al poema. El análisis propone, finalmente, cinco dimensiones en que la relación silencio-daño ha sido asumida por la poesía que en las últimas tres décadas se ha acercado al fenómeno de la violencia en Colombia: el silencio frente al acontecimiento, el silencio de la ausencia, la imposición del silencio -donde es posible identificar manifestaciones como la palabra equivocada y la poesía silenciada-, la palabra imposible y la palabra ignorada.

Palabras clave: Silencio; daño; poesía colombiana.

RESUMO: Partindo de alguns esforços de desambiguação do silêncio relativo a experiência do dano, o artículo analisa as maneiras, temáticas e expressivas, com que a recente poesia colombiana da violência assume o silêncio como objeto de reflexão poética. $O$ texto inicia com uma revisão em torno a formulações teóricas que se têm aproximado, desde a sociologia e a filosofia política, a classificação das possibilidades de significação do silêncio na sua dimensão política, estreitamente relacionada com as práticas e os discursos da violência em Colômbia. Posteriormente, empreende a analise dos campos semânticos e das estruturas sintáticas e de enunciação de um grupo de poemas para estabelecer as formas em que o referido silêncio ingressa no poema. A analise estabelece, finalmente, cinco dimensões em que a relação silêncio-dano tem sido assumida pela poesia que nas últimas três décadas se tem aproximado do fenómeno da violência em Colômbia: o silêncio frente ao acontecimento, o silêncio da ausência, a imposição do silêncio - onde é possível identificar manifestações como a palavra errada e a poesia silenciada -, a palavra impossível e a palavra ignorada.

Palavras-chave: Silêncio, dano; poesia colombiana.

\footnotetext{
${ }^{1}$ Doctorando en Humanidades de la Universidad EAFIT, Medellín, Colombia. Adscrito al grupo de investigación Estudios en Filosofia, Hermenéutica y Narrativas, del Departamento de Humanidades de la Universidad EAFIT, Medellin, Colombia.
} 


\section{Introducción: hacia una desambiguación del silencio en relación con la experiencia del daño}

Más que una sustancia, dice David Le Breton, el silencio es una relación (2016, p. 57). Su significación, siempre ambigua, está entonces vinculada tanto al contexto inmediato de la interacción comunicativa como a las coordenadas históricas y culturales del lugar y el momento en que se produce. En este sentido, uno de los escenarios de mayor presencia e influencia del silencio es el de la experiencia del daño ${ }^{2}$, donde el acto de callar adquiere diversas posibilidades de significación, relacionadas con las etapas del daño, con los agentes que lo experimentan o lo imponen -víctimas, victimarios, terceras figuras-, así como con la intencionalidad misma del callar o del silenciar, entre otras condiciones. Es justamente este encuentro entre experiencia del daño y silencio el que se entiende aquí como los silencios del daño ${ }^{3}$. Tras un repaso por algunos esfuerzos de desambiguación del silencio en relación con el daño, este texto se aproxima a la manera en que la poesía de la violencia en Colombia -específicamente aquella de las últimas tres décadas- ha asumido esta relación; si bien se aborda desde una perspectiva principalmente temática, el análisis contempla tanto los mecanismos expresivos como enunciativos que inciden en la manera en que el silencio ingresa y se hace significativo en el poema. Para este caso, se analizarán poemas de José Manuel Arango, María Mercedes Carranza, Horacio Benavides, Pedro Arturo Estrada y Hellman Pardo.

Entre los esfuerzos de desambiguación del silencio como práctica relacionada con el daño, se encuentra la formulación de tipologías que, desde la sociología y la filosofía política, han emprendido autores como Rigoberto Reyes Sánchez, David Le Breton, Carlos Thiebaut, Wolfgang Heuer y Alfredo Fierro, cuyos aportes serán descritos en este apartado introductorio. Se trata, en pocas palabras, de clasificaciones sobre las motivaciones y manifestaciones del silencio en su dimensión política.

Tal vez, el autor que plantea la tipología más general del silencio en relación con el daño es Rigoberto Reyes Sánchez, en su trabajo «Enmudecer, acallar, guardar. Violencia y silencio en el México contemporáneo» (2017), donde busca aproximarse al silencio de los cuerpos con el fin de «contribuir a comprender de otro modo tanto las dinámicas de las distintas expresiones de violencia como las formas de insubordinación y resistencia que surgen contra ellas» (2017, p. 259). En la medida en que, dice Reyes, el silencio absoluto se presenta únicamente en el cuerpo muerto, prefiere hablar de "tonos y acentos afectivo-políticos del silencio" para referirse a lo que les sucede a los cuerpos vivientes (2017, p. 261). Su énfasis en trabajar el silencio de los cuerpos -o en los cuerpos- reduce, en cierta medida, las posibilidades del silencio a quienes lo padecen, a excepción de las dos manifestaciones que desarrolla en la última tonalidad, donde incluye las

\footnotetext{
${ }^{2}$ Thiebaut se refiere a la experiencia del daño para hablar de «los procesos, las acciones, las relaciones [...] que producen negatividad física, psíquica, cultural o moral (como una herida, una lesión, una condición lesiva de intereses y derechos) en una persona por medio de una acción intencional o una omisión» (2017b, p.11). Para Thiebaut, el alcance de este concepto trasciende el acto de dañar y de sufrir el daño y alberga los procesos de elaboración, sentido y demandas normativas, derivados de la experiencia. Si bien en las reflexiones sobre el daño ha primado el énfasis ya sea en las víctimas o en los victimarios, Thiebaut ha llamado la atención sobre la relevancia de las terceras figuras, entendido comúnmente como «espectador»; sin embargo, es justamente ahí donde podría ubicarse también la reflexión surgida del arte y, en este caso, de la literatura, con relación a las experiencias del daño.

3 "Daño y silencio» (2017) es el nombre del texto en el que Carlos Thiebaut desarrolla esta relación, donde, no obstante, no aparece un nombre específico para denominar la tipología. En la actualidad, Thiebaut trabaja en el libro Las tareas del daño, donde dedica uno de los capítulos -el primero de los «excursos»- a este vínculo, al que llama de manera específica «los silencios del daño».
} 
voces de terceros - poeta y sociedad-. A pesar de esta focalización, las categorías sugeridas por Reyes constituyen una importante aproximación para la comprensión de que los silencios de la víctima abarcan diversos ámbitos, relacionados principalmente con los motivos que los generan, así como quién los impone o el marco en que se producen. Entre estos, como se observa a continuación, se encuentran el acallamiento, el silenciamiento y el guardar silencio ${ }^{4}$.

Figura 1 - Tonalidades afectivo-políticas del silencio

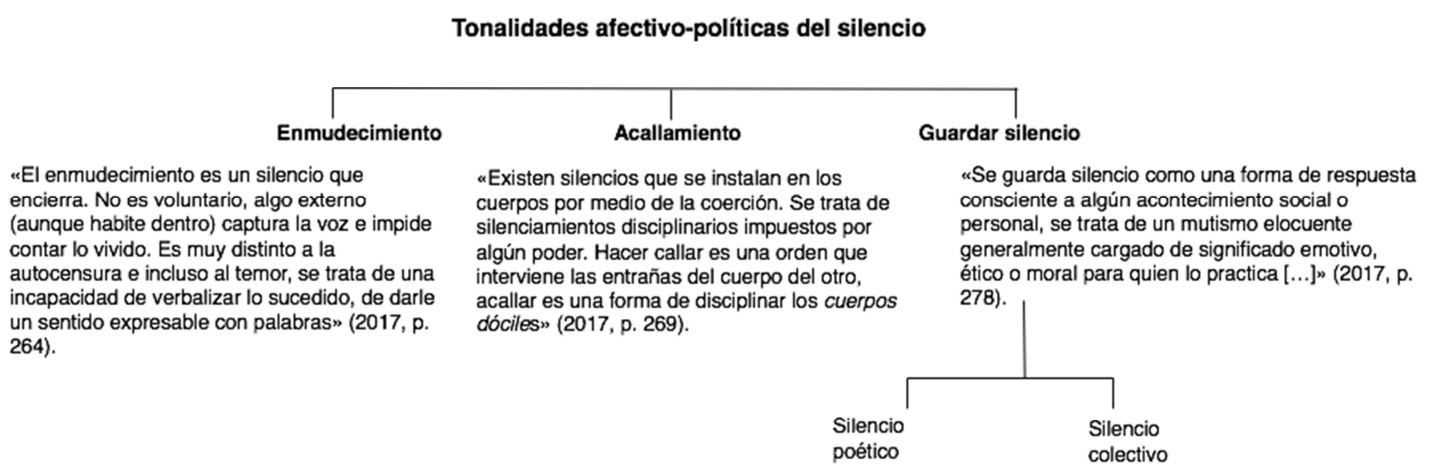

El desarrollo de lo que Reyes denomina «silencio poético» podría entenderse desde dos perspectivas: de un lado, como el trabajo que debe hacer el poeta al intentar nombrar el mundo con las ruinas del lenguaje, «usar el lenguaje de un modo distinto al de los perpetradores», como lo hizo Paul Celan; de otro, más que de un «silencio poético», sería más preciso hablar del silencio del poeta, pues Reyes se refiere al caso del poeta mexicano Javier Sicilia, quien, tras enterarse del asesinato de su hijo, escribió un último poema ${ }^{5}$ y abandonó el oficio, a manera de protesta política contra la violencia (REYES, 2017, pp. 280 - 281).

Desde una perspectiva sociológica, David Le Breton elabora un amplio estudio del silencio y dedica uno de sus capítulos a lo que denomina «las políticas del silencio», donde se centra en las manifestaciones del silencio impuesto por la violencia, aquel que destruye el vínculo social. Si bien en esas páginas incluye varias expresiones, no todas están relacionadas en forma directa con el problema del daño, por lo que -como se detalla en el diagrama a continuación- se presentan únicamente las que resultan pertinentes para el diálogo con la experiencia del daño.

\footnotetext{
${ }^{4}$ Es importante aclarar que no todos los autores se refieren de manera explícita al término "tipología» para denominar sus aportes en la diferenciación del silencio, y que ninguno de ellos avanza en una visualización gráfica, como se propone en este abordaje; la intención de los diagramas es acentuar aun más las diferencias en estos antecedentes de la búsqueda por desambiguar las posibles significaciones del silencio en contextos de daño.

${ }^{5}$ Los siguientes son los versos del poema recogidos en el artículo de Reyes: «Ya no hay más que decir / El mundo ya no es digno de la Palabra / Nos la ahogaron adentro / Como te asfixiaron / Como te desgarraron a ti los pulmones / Y el dolor no se me aparta / Solo pervive el mundo por un puñado de justos / Por tu silencio y el mío / Juanelo (SICILIA en REYES, 2017, p. 281).
} 
Figura 2 - Las políticas del silencio

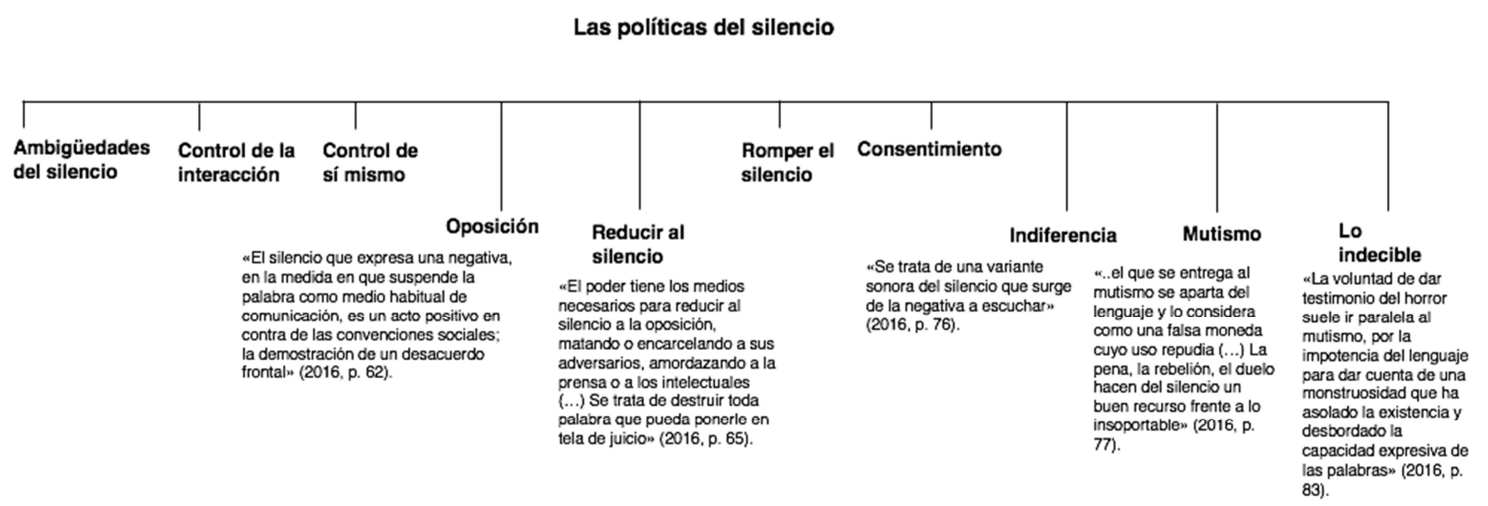

Sin que la propuesta de Le Breton esté organizada en relación con el agente que produce o experimenta el silencio, es claro que las categorías de «oposición» y «mutismo» se configuran como espacios del silencio como respuesta, mientras que la categoría de «reducir al silencio» obedece a la imposición del silencio por parte de quien ejerce determinado poder. En esta última no siempre se busca el silenciamiento pero, de todas maneras, en situaciones como el exilio, el encarcelamiento o el aislamiento este se presenta como consecuencia. Con respecto a la «indiferencia», si bien el énfasis del autor se circunscribe al plano individual de quien la padece $-«[i]$ ndividuos sin filiación, que a duras penas se mantienen en el ámbito social, pero que no despiertan el más mínimo interés en los que les rodean» (LE BRETON, 2016, p. 76)-, es una categoría perfectamente trasladable al ámbito de lo colectivo-activo, tanto en la actitud de las instituciones como de la sociedad misma frente a quienes han sufrido la violencia. De hecho, junto con el olvido, Le Breton incluye la indiferencia como una forma radical de «descalificación del significado» ante la experiencia de «lo indecible». Esta última experiencia -la de «lo indecible»- se relaciona con la categoría de «enmudecimiento» de Reyes Sánchez (2017) o de «no poder hablar» de Thiebaut (2017), pero en el caso de Le Breton está presente también el deseo de contar que antecede al testimonio frustrado: «[i]mposibilidad de decir y de callarse, cruel indecisión entre dos necesidades igual de poderosas, dolor que produce una tensión imposible de aliviar» (2016, p. 83).

Bajo la idea de que existen silencios negativos y positivos, Carlos Thiebaut elabora su estudio «Daño y silencio» (2017) con la intención de adentrarse en la comprensión del silencio a partir de la tesis de que este «tiene significados diferentes según sean sus contextos y su carácter performativo» (2017, p. 220). La de Thiebaut se configura como la tipología más amplia y la que más perspectivas abarca, pues no solo integra los silencios de quien padece y de quien inflige el daño sino que tiene en cuenta a los terceros, a quienes se ven interpelados por el daño; a estos últimos hace referencia en la categoría de silencios positivos: "El silencio positivo es aquel que ejercen, como espectadores concernidos y como acompañantes implicados en la elaboración del daño, quienes perciben ese daño y se sienten interpelados [...] es, ante todo, el del acompañante concernido en el daño y su trabajo» (2017, p. 243). 
Figura 3 - Daño y silencio

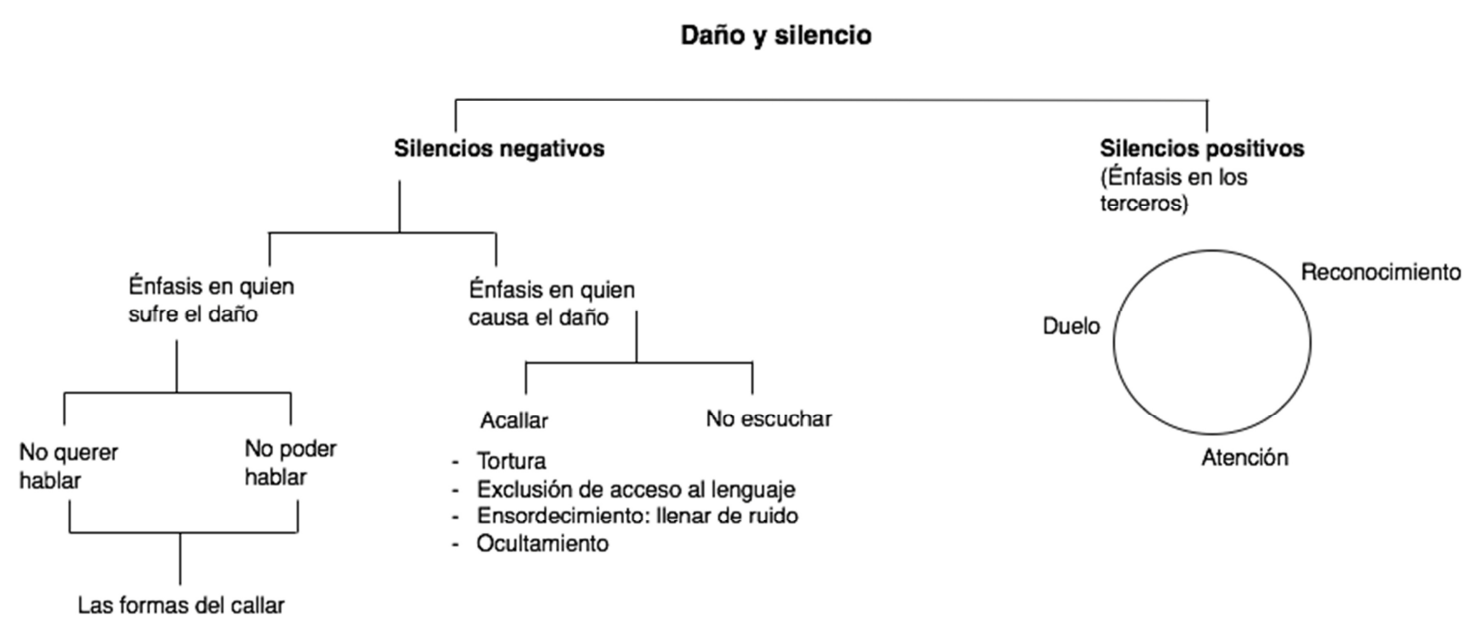

El esquema de Thiebaut permite, no obstante, pensar también que expresiones como la exclusión del acceso al lenguaje, el ensordecimiento, el ocultamiento o el no escuchar, si bien pueden ser motivadas directamente por los perpetradores del daño, también son muchas veces producto de la actitud de displicencia o indiferencia de las instituciones o de la sociedad misma -los terceros, «los espectadores»-, por lo que podría considerarse una categoría de silencios negativos relacionada con los no involucrados en forma directa en la experiencia del daño.

Wolfgang Heuer, por su parte, elabora el análisis titulado «Volver a hablar tras la muerte del lenguaje» (2017), donde, con base en lo ocurrido con el Holocausto en la Alemania nazi, propone cuatro motivaciones para intentar describir lo que entiende como el «silencio múltiple» o el silenciamiento de la experiencia.

Figura 4 - Silencio múltiple

\section{Silencio múltiple}

\begin{tabular}{|c|c|c|c|}
\hline $\begin{array}{l}\text { Miedo de los } \\
\text { perpetradores } \\
\text { al castigo }\end{array}$ & $\begin{array}{l}\text { Vergüenza por haber } \\
\text { colaborado en algo que } \\
\text { culminó en crimenes } \\
\text { inéditos }\end{array}$ & $\begin{array}{l}\text { Incapacidad de } \\
\text { hablar por las } \\
\text { experiencias } \\
\text { traumáticas de los } \\
\text { soldados }\end{array}$ & $\begin{array}{l}\text { Incapacidad de hablar } \\
\text { de lo vivido, por la } \\
\text { disposición ausente } \\
\text { de escuchar a otros }\end{array}$ \\
\hline
\end{tabular}

De entrada, podría objetarse la denominación general de Heuer, pues todo silencio es múltiple: «El silencio no tiene un significado unívoco, pues su orientación depende de cada específica circulación social de la comunicación» (LE BRETON, 2016, p. 55); es entones cada situación particular la que permite delimitar y orientar el sentido de la ausencia de palabras. La formulación de Heuer se centra en el caso alemán y aborda el silencio que se instaló durante las décadas posteriores a la Segunda Guerra Mundial. En palabras de George Steiner:

Millones de alemanes comenzaron a comentar entre ellos y a decir a los extranjeros crédulos que les atendían que lo que se contaba del pasado no era del todo cierto, que los horrores habían sido enormemente exagerados por la 
propaganda aliada y el periodismo sensacionalista (2013, p. 136).

Si bien la perspectiva de Heuer es reducida -tal como la de Reyes (2017)-, pues se focaliza en los perpetradores del daño, ofrece un panorama diverso para aproximarse a lo que sería una especie de silencio institucional; de hecho, pocos esfuerzos de clasificación del silencio se ocupan de profundizar en motivaciones como la vergüenza o la culpa, que no son del ámbito exclusivo de los victimarios: como recuerda Giorgio Agamben, el sentimiento predominante entre los sobrevivientes de Auschwitz era el de la vergüenza (2009, p. 135).

Por último, desde una aproximación que vincula la filosofía y los estudios del discurso, en su ensayo "La conducta del silencio» (1992), Alfredo Fierro reconoce que el silencio «remite, por sí mismo, a contenidos y procesos mentales que la palabra no es capaz de tomar a su cargo» (1992, p. 55) y profundiza en ámbitos en los que el silencio se relaciona con el pensamiento, el deseo, la práctica, el final -la muerte- y las instituciones culturales. Justamente, es en este último contexto - «las instituciones culturales del silencio»- donde Fierro inscribe las manifestaciones de los que denomina «los silencios vinculados al poder», de los que es posible extraer una tipología vinculada con la experiencia del daño.

Figura 5 - Silencios vinculados al poder

Silencios vinculados al poder

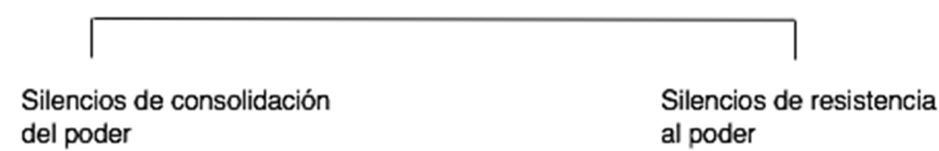

Entre los silencios de consolidación del poder, Fierro incluye manifestaciones como los secretos de Estado, los secretos militares, las materias reservadas de las que no se habla o «el silencio que a veces sigue al "enterado" de la suprema magistratura respecto a una sentencia de muerte» (1992, p. 73). Entre los silencios de resistencia al poder, Fierro se refiere en particular a los silencios de las víctimas, donde incluye específicamente el «silencio, bajo torturas, ante inquisidores religiosos o policiales, de quien se niega a confesar inexistentes crímenes o a delatar a otros compañeros»; en este último apartado hace referencia también al minuto de silencio, que puede o puede no estar relacionado con una actitud de protesta o resistencia frente al poder (1992, pp. 73 - 74).

\section{Los silencios del daño en la poesía colombiana}

En la poesía que en los últimos años se ha acercado a la violencia en Colombia, el silencio se configura como uno de los objetos de reflexión poética más frecuentados. Si bien en varios de los poemas son perceptibles algunas de las tipologías propuestas por los autores mencionados en el apartado introductorio, el análisis permite evidenciar que los poemas mismos proponen maneras particulares de abordar la reflexión sobre la práctica del silencio, por lo que es posible establecer unas categorías surgidas de estos. Más que de forzar el contenido de los poemas para que coincida directamente con las formulaciones teóricas, se trata 
entonces de establecer ciertas recurrencias temáticas que -junto con los mecanismos retóricos del silencio- proponen diversas maneras de aproximación a la carga semántica del silencio relacionado con el daño; entre estas consideraciones se encuentran entonces el silencio frente al acontecimiento, el silencio de la ausencia, la imposición del silencio -donde es posible identificar manifestaciones como la palabra equivocada y la poesía silenciada-, la palabra imposible y la palabra ignorada.

\subsection{El silencio frente al acontecimiento}

En sus reflexiones sobre la novela de la Violencia de mediados del siglo XX, Gabriel García Márquez cuestionaba el tratamiento ficcional del fenómeno, al que le reclamaba el haberse reducido a un inventario de los muertos y haber ignorado que lo más importante, desde el punto de vista humano -y, por tanto, literario-, eran los vivos (1959/2014). Buena parte de este inventario ocupó también el ámbito de la poesía, como puede leerse en poemas como «Tortura de Julio Rincón», de Jorge Gaitán Durán (en GALEANO, 1997, pp. 105 - 107), o «Los presagios de la lluvia», de Fernando Arbeláez (en LUQUE, 1996, pp. 188 - 192), entre otros, cuyas escenas describían explícitamente los mecanismos del horror y las acciones llevadas a cabo por los bandos en disputa durante la confrontación bipartidista. Uno de los casos más evidentes es el poema «Las hijas del muerto», de Jaime Jaramillo Escobar, publicado en 1983, donde se describen las prácticas del conflicto en los siguientes términos:

Y la venganza. Y el odio. No somos un pueblo carente de imaginación: si se le cortaba a alguien la cabeza, se le metían por el cuello las manos cortadas y se exhibía «el florero». Se abría la piel por el pecho, se extendía a los lados y se mostraba "el murciélago». En el camino de Urrao se castraba a los hombres a golpe de mazo. El poema no admite más ejemplos. Acudid a las actas $(1983 / 2000$, p. 150).

Tras la cruda descripción de la sevicia ${ }^{6}$ con que era tratado el cuerpo del contrincante, el hablante reconoce que «el poema no admite más ejemplos»y le da la instrucción al lector para que, en caso de que requiera información sobre el hecho, acuda a las actas. El contraste entre la exhibición textual del daño y el reconocimiento de que el poema no es espacio para la constatación fáctica opera como una especie de antecedente anecdótico de la tendencia del discurso poético reciente, que tiende a eludir o callar el acontecimiento violento. Aun cuando el poema guarde un anclaje directo con respecto al referente histórico, es el propio decir poético el que se asume como acontecimiento ${ }^{7}$ :

\footnotetext{
${ }^{6}$ De acuerdo con el Centro Nacional de Memoria Histórica (CNMH), la sevicia se entiende como «la causación de lesiones más allá de las necesarias para matar. Es decir, es el exceso de la violencia y la crueldad extrema que tiene como expresión límite el cuerpo mutilado y fragmentado» (2013, p. 54).

${ }^{7}$ Son los estudios sobre el discurso los que permiten entender el poema como acontecimiento. A partir de la oposición entre discurso y lengua, Paul Ricoeur establece que, mientras esta última se entiende como un sistema abstracto, virtual y ajeno al tiempo, el discurso se realiza en el tiempo, remite a un hablante y «es siempre a propósito de algo: se refiere a un mundo que pretende describir, expresar o representar» (2010, p. 98). En este sentido, es posible asumir el texto poético como un tipo de discurso que, además de los procesos de significación que elabora con recursos como los mecanismos de enunciación, la estructura sintáctica, la materialidad de la palabra, el sonido o la imagen, reconoce que se inscribe y participa de una realidad histórica particular.
} 
La obra de arte o el poema dicen su propia acontecibilidad nacida tal vez de una acontecibilidad externa, pero, borrándola, ellos crean la acontecibilidad de su decir; y es a esa acontecibilidad a la que el espectador o lector reacciona, remontando eventualmente la acontecibilidad externa, histórica (NOUSS, 2006, pp. 77 - 78).

Si bien son diversas las posibilidades en que la reciente poesía de la violencia elude la referencia al acontecimiento del daño, es en los poemas con un anclaje directo en el referente histórico donde con mayor claridad se podría constatar el mencionado silencio frente al acontecimiento. De hecho, en poemarios como El canto de las moscas (1998/2014), de María Mercedes Carranza, o en Los días derrotados (2016), de Hellman Pardo, se emplean recursos textuales que explicitan la ambigüedad que se abre entre el nombrar y el callar. Además de los nombres propios con los que se designan los poemas -nombres de poblaciones víctimas de masacres en Colombia-, el título del poemario de Carranza está acompañado por el enunciado (Versión de los acontecimientos), elemento paratextual que remite a un «acontecimiento» anterior al texto y que, junto con la idea de "versión», sugiere cierta recreación particular de los hechos. Sin embargo, la versión propuesta por los poemas se encarga de silenciar los sucesos y poner el énfasis en la ausencia de porvenir, en un «cementerio de sueños» (CARRANZA, 2014, p. 154). Así ocurre, por ejemplo, con el poema «Mapiripán» ${ }^{8}$ :

\section{Canto 2}

\section{Mapiripán}

Quieto el viento, el tiempo.

Mapiripán es ya

una fecha.

(CARRANZA, 2014, p. 134)

Más que a una indicación espacial, el uso del nombre propio del lugar del daño activa un desplazamiento hacia la carga temporal del acontecimiento de la masacre; desplazamiento que se hace explícito en "Mapiripán», donde el nombre-espacio ha sido reducido a un dato temporal. No se trata, no obstante, de una temporalidad que discurre sino de una estática: de un lado, el adjetivo «quieto», que por anteceder a la imagen del viento -única posibilidad de movimiento en el poema- lo inmoviliza, opera también para el sustantivo «tiempo»; de otro, la idea de fecha carece de continuidad; una fecha se fija, se instala, y así lo ratifica el adverbio "ya» del verso 3, cuya acepción no debe leerse en el sentido de ahora o inmediatamente sino en el de tiempo u ocasión pasados. La isotopía reinante es entonces la de la inmovilidad: el referente evocado por el nombre del poema activa tanto la temporalidad previa al acontecimiento, la del fluir del tiempo vital, como la de la ausencia de movimiento, ausencia de vida, instalada por el poema. También la predominancia nominativa y la ausencia de verbos, advertidas en el análisis de Beatriz Vanegas - «[s]olo tiene un verbo de estado o copulativo, el verbo es (ser)» (2008, p.

\footnotetext{
${ }^{8}$ Tanto este poema de María Mercedes Carranza como el de Hellman Pardo, que lleva el mismo nombre y que será abordado enseguida, remontan la acontecibilidad externa o histórica -para decirlo con Nouss- de la masacre de Mapiripán -municipio del departamento del Meta-, ejecutada por grupos paramilitares en 1997.
} 
37)-, refuerzan el carácter estático del ambiente sugerido por el poema.

En el caso de Los días derrotados, de Hellman Pardo, son los nombres de los poemas de la primera parte -vinculados también con poblaciones víctimas de masacres- los que están acompañados por enunciados en paréntesis que, en algunos casos, remiten también a una reconstrucción verbal de los acontecimientos; entre estos, se encuentran términos como "crónica», «historia» o «discurso», que claramente sugieren nuevas aproximaciones a referentes espacio-temporales - más temporales que espaciales- que activan la carga histórica de las masacres en Colombia. Tal como lo hace Carranza, también Pardo dedica uno de los poemas al caso de Mapiripán:

\section{Mapiripán (Los pliegues del agua)}

(I) No es el golpe invernal de árboles dolidos que tropiezan con la noche

o el rencor de las luciérnagas

cuando naufragan por el aire

y llevan a media asta las alas húmedas

de abandono.

(II) No es la fatiga del valle

tardío arrepentimiento de cuchillos jubilados.

(III) No es el hambre

$$
\text { o su llanto en el estómago. }
$$

(IV) Asciende una fiebre imperturbable en aguas solísimas.

$$
\begin{aligned}
& \text { Es el río Guaviare } \\
& \text { madre } \\
& \quad \text { su aguacero } \\
& \text { estanque de cuerpos condenados } \\
& \text { donde lavabas y herías la ropa contra las piedras } \\
& \text { de tus pechos. }
\end{aligned}
$$

(PARDO, 2016, p. 16)

El poema sugiere dos momentos, identificados a partir de la estructura enunciativa de las estrofas: el primer momento, en las estrofas I, II y III, construido a partir de la negación, remite a cierto malestar; el segundo momento -que, en contraste con la negación de las primeras tres estrofas, podría entenderse como afirmativo- ocupa las estrofas IV y $\mathrm{V}$ y alberga la imagen que -junto con el nombre- configura la alusión al daño. Entre los versos 1 - 10, la negación -explícita en los versos 1,7 y 9- pareciera tratar de explicarle a un tú -la madrecuáles no son las causas del malestar. Si bien aparecen imágenes que evocan dolor, cansancio, culpa, carencia o abandono -que en la primera estrofa acompañan sustantivos asociados con lo positivo: árboles, luciérnagas, alas-, es la negación la que indica que hay algo más allá de estas condiciones que se ha instalado y rige el temple afectivo del pueblo. Para los versos 11 y 12 ha 
desaparecido la negación y pareciera configurarse una transición -«Asciende una fiebre imperturbable»- que deriva en la causa buscada: «Es el río Guaviare», convertido en «estanque de cuerpos condenados», aquello en lo que recae un malestar más profundo que el sugerido en las primeras tres estrofas. Como señala el $\mathrm{CNMH}$, «[l]os actores armados convirtieron a los ríos en fosas comunes» (2013, p. 62), y la masacre de Mapiripán no fue la excepción: al río Guaviare fueron a dar los restos de algunos de los 49 civiles asesinados durante los hechos (CNMH, 2013, p. 408). De ahí que en este poema de Pardo sea el río en donde repose el peso del daño: el fluir de la vida -como el dinamismo del viento en el poema de Carranza-, por arduo que fuera, es ahora un estanque -quieto- de agua y de cuerpos. La idea misma de pliegue, en el paréntesis que acompaña el título del poema, sugiere también un doblez, un mirar la otra cara, un poner atención a lo que oculta el agua.

Los dos poemas analizados permiten conocer dos aproximaciones poéticas a un mismo referente histórico, ninguna de las cuales se funda sobre la base de una reelaboración discursivopoética de los hechos. En ambos casos la acontecibilidad externa es eludida; desaparece el inventario de muertos en aras de la instalación de un tiempo de quietud que se opone al discurrir de la vida, a partir de metáforas que evocan los campos semánticos de esta tensión y de los recursos enunciativos del poema. Claramente, no se trata de un silencio de reticencia, ocultamiento, indiferencia u olvido, pues el uso del nombre propio activa la memoria sobre el hecho; lo que se presenta es más bien un desplazamiento en el énfasis del contenido.

\subsection{El silencio de la ausencia}

Uno de los escenarios más frecuentes en la poesía reciente de la violencia en Colombia tiene que ver con el hablar desde la ausencia; es decir, poemas en los que el hablante se ubica en el no-lugar de la muerte y desde allí, desde ese espacio en que se es voz pero no cuerpo, se rinde testimonio de la experiencia del daño ${ }^{9}$. El otro polo de la ausencia como experiencia del daño, también recurrente en la poesía de la violencia y que no aparece desarrollado en las tipologías de desambiguación del silencio, es el de la figura presente -también víctima- que reclama a su vez la presencia de quien ya no está. Se trata de poemas que no solo constatan la corporalidad ausente que "ocupa» un vacío, sino que abordan diálogos imposibles, expectativas que quedan sin respuesta. De hecho, en ocasiones, además de la presencia de ese otro, el reclamo deriva en el ruego por una palabra, por una certeza de lo que ocurrió con ese otro, por una versión que permita el descanso. Ese desplazamiento en la demanda de quien espera es tematizado en el siguiente poema de Pedro Arturo Estrada:

\section{País de silencio}

Alguien se atreve a preguntar por el que no ha vuelto.

Y las sombras le contestan: nada, nadie, ninguno.

Alguien deambula husmeando los últimos pasos,

los ayes que dejó en el aire, las voces que aún

\footnotetext{
${ }^{9}$ Más que una manifestación del silencio, la enunciación desde el no-lugar de la muerte puede ser asumida como un espacio de silencio. Dicho espacio es una constante en poemarios como Conversación a oscuras (2014), de Horacio Benavides, Reino de peregrinaciones (2017), de Hellman Pardo, o Diario de los seres anónimos (2015), de Ómar Ortiz. También pueden incluirse en esta ubicación de la voz hablante poemas como "De la muchacha asesinada", de Pedro Arturo Estrada (2006) y «Falso positivo (su voz)», de Leonardo Torres (en RESTREPO, 2014), entre otros.
} 
se cuelan por debajo de las puertas. Alguien

bajo las sábanas húmedas de la medianoche

no logra conciliar el sueño, espera hasta la alta

desolación del alba esa noticia, ese ya, ese basta,

ese grito final que restablezca el curso de los días

y desate la voz sobre el vacío

excavado por años de silencio

y miedo.

(ESTRADA, 2006, p. 29)

La carencia de un yo en la enunciación, la indeterminación expresada por el pronombre «alguien» en los versos 1,3 y 5 y el nombre común del título - «país»- inscriben el poema en un contexto de generalización, donde más que a una figura -no identificada- el mencionado pronombre se acercaría a la posibilidad de un «todos» o de un «cualquiera»; ocurre lo mismo con aquel que es objeto de la espera. La singularidad indeterminada de ese «alguien» sugiere entonces una pluralidad constante de situaciones similares -las tres apariciones podrían leerse como tres agentes distintos- en la marca territorial que implica el sustantivo "país», cuya totalidad se ve caracterizada por el sintagma preposicional «de silencio», recurso que se repite en poemas como "País de nadie» y «País de palomas», también del poemario Oscura edad y otros poemas (2006). No se trata de un caso específico de ausencia sino de un país impregnado de ella, de silencio.

La isotopía del silencio, explícitamente nombrada en el título del poema -así como en el verso $11-$, es construida además con palabras como «sombras», «nada», «nadie», «ninguno», que caracterizan la ausencia de respuesta -o negación- que rige los versos 1 y 2 del poema. Tras la pregunta del verso 1 , se presenta, posteriormente, una especie de búsqueda, en los versos 3 - 5, y, por último, una espera, que iniciaría con el insomnio en los versos 6 y 7 y que se extiende hasta el verso 12. Pero si la búsqueda -«alguien deambula husmeando»- está orientada por los vestigios de aquel que «no ha vuelto», particularmente por sus "pasos», sus «ayes» y sus «voces», la espera se desplaza hacia la demanda por una "noticia», por una información que, al leerse como «ese ya», «ese basta», "ese grito final», abriría la posibilidad de la resignación «que reestablezca el curso de los días», no ya con un regreso de la presencia sino con una certeza que quiebre el silencio de la ausencia o que lo desplace, quizá, a uno positivo, a ese silencio como «ropaje casi imprescindible del duelo» (THIEBAUT, 2017, p. 242).

Quien espera se debate entre el ahora/aquí del esperar y el después/allí de lo esperado; es decir, una especie de temporalidad/espacialidad indeterminada o en tensión constante entre lo que es y lo que podría ser. Y si en "País de silencio» la espera inicial deviene desesperanza resignación frente a la no presencia de aquel «que no ha vuelto»- y ansia de certeza, en "-iQué hace ese hombre sentado...», de Horacio Benavides, se evidencia la mencionada fractura espacio-temporal de un sujeto que en su espera alberga la esperanza - «parece cosa segura que en la vida del hombre no hay espera sin esperanza» (1978, p. 10), decía Pedro Laín Entralgo-; una esperanza que, a medida que pasa el tiempo, no solo se va borrando ella misma sino que arrastra también a quien la alberga:

(I) - ¿QUÉ HACE ese hombre sentado

día y noche en el parque? 
(II) - Espera a sus hijos, piensa que en cualquier momento pueden regresar

(III) - ¿Y desde cuándo espera?

(IV) - Desde que se los llevaron Se va y vuelve el invierno y él sigue ahí El tiempo lo ha ido borrando, lo que usted ve es su alma

(V) - ¿Y sus hijos volverán?

(VI) - Nadie ha regresado, pero él ha atado a sus muchachos con un hilo de esperanza

(BENAVIDES, 2014)

Tampoco aparece aquí el yo como hablante de la experiencia de la espera. El poema se construye, en cambio, como un diálogo en el que los interlocutores describen la «actividad» de un hombre que espera día y noche, de invierno a invierno, el regreso de sus hijos. La experiencia del daño aparece en el verso 7, pues se sugiere que los hijos del hombre fueron llevados contra su voluntad, ruptura que abre una doble ausencia: no solo faltan los hijos; el verse abocado hacia la temporalidad futura -por medio de la metáfora del «hilo de esperanza»va desdibujando la presencia misma del hombre que se ve reducido a su alma.

\subsection{La imposición del silencio}

La imposición del silencio es tal vez la más explícita de las expresiones de la violencia directa (GALTUNG, 1981, p. 95) relacionada con la palabra y tiene que ver con la coacción ejercida por los victimarios para silenciar al otro. En los esquemas de Reyes Sánchez (2017) y de Thiebaut (2017) esta práctica se denomina «acallamiento»; en el segundo, hace parte de los silencios negativos con énfasis en quien causa el daño e incluye prácticas como la tortura, la exclusión del acceso al lenguaje, el ensordecimiento y el ocultamiento. Le Breton (2016), por su parte, la llama «reducir al silencio»e inscribe en esta categoría manifestaciones como la censura, el control de la lengua o la falta de ella, el silencio del vencido o el aislamiento. La amplitud del ámbito abarcado por los silencios que se desprenden del ejercicio de la fuerza permitiría pensar que toda acción violenta implica, de una u otra manera, el advenimiento de alguna forma de silencio. En ese sentido, podría afirmarse también que toda poesía dedicada a la experiencia del daño alberga en sus versos una reflexión sobre el silencio impuesto.

No obstante, a pesar de esta presencia constante de la imposición del silencio, es posible identificar en la poesía de la violencia en Colombia recurrencias que profundizan en la reflexión sobre el acallamiento y que permiten posicionarlo como una manifestación temática diferenciada. En dichas recurrencias se destacan las referencias a la práctica de la tortura, que será analizada desde la lógica de «la palabra equivocada», y el silenciamiento de voces, que trasciende el alcance del contenido del poema para abarcar la situación misma del autor 
empírico, en lo que podría entenderse como «la poesía silenciada».

\subsubsection{La palabra equivocada}

Un sub-apartado dedicado a la tortura bien podría llamarse también «la palabra arrancada» o "la palabra arrebatada», para usar los términos de Sophia McClennen, pues su propósito es el de arrancar el lenguaje de la voz, arrebatar brutalmente un lenguaje del cuerpo (2004, p. 68). Y es que, en cierta medida, la tortura no impone el silencio sino que busca romperlo $^{10}$. De acuerdo con Elaine Scarry, se trata de un mecanismo de violencia que, por lo general, comprende dos actos: uno verbal, interrogar -la pregunta y la respuesta-; otro físico, infligir dolor (1987, p. 28). Justamente, sin ignorar el segundo acto, los poemas -en tanto espacios de problematización de la palabra- ponen su énfasis en el primero, en el acto verbal. Así ocurre en el poema «Fe de erratas», de José Manuel Arango.

\section{Fe de erratas}

(I) Ha equivocado la palabra

(II) donde dijo sí

quizá

debió decir no

y tal vez un poco más tarde

donde dijo no

debió decir sí

(III) El carpintero -el lápiz en la oreja- toma sus medidas

(IV) Un helicóptero pasa volando sobre las terrazas

(V) Soldados de cabeza rapada vigilan las calles

(ARANGO, 2015, p. 156)

Como buena parte de los poemas de Cantiga (1987/2015), «Fe de erratas» carece de la presencia de un yo; la voz se construye desde la perspectiva impersonal de la tercera persona. Si bien podría pensarse que la violencia se hace presente por medio de las imágenes de los tres últimos versos -el ataúd no mencionado del verso 8 , el helicóptero en las terrazas del verso 9 y los soldados en las calles del verso 10-, estas operan más bien como contexto y resolución; la

\footnotetext{
${ }^{10}$ Tanto para Thiebaut como para el CNMH, la tortura trasciende en muchos casos el objetivo de la obtención de información. Para el primero, esta práctica presenta una paradoja, en la medida en que busca que la víctima articule un lenguaje; sin embargo, señala Thiebaut, «no es infrecuente, y quizá sea su sentido profundo, que la tortura no tenga ese fin ni ese efecto aterradoramente policial sino que se estructure como un proceso de destrucción de la víctima» (2017, p. 236). Por su parte, el CNMH define la tortura a partir de la Convención para la tortura aprobada por la Ley 70 de 1986: «todo acto por el cual se inflija intencionalmente a una persona dolores o sufrimientos graves, ya sean físicos o mentales, con el fin de obtener de ella o de un tercero información o una confesión, de castigarla por un acto que haya cometido, o se sospeche que ha cometido, o de intimidar o coaccionar a esa persona o a otras, o por cualquier tipo de discriminación, cuando dichos dolores o sufrimientos sean infligidos por un funcionario público u otra persona en el ejercicio de funciones públicas, a instigación suya, o con su consentimiento y aquiescencia» (2013, p. 56).
} 
carga de violencia en realidad se ejerce sobre la palabra de aquel que la ha equivocado. La indeterminación expresada por los adverbios «quizá», en el verso 3, y «tal vez», en el verso 5, junto con la oposición «sí» y «no» de las dos preguntas no incluidas -pero sí evocadas en dos momentos distintos-, indica que no había ya respuesta posible. Se trata de una palabra quebrada, insuficiente, cuyas imposibilidades se ven acentuadas por la ausencia de pronombres personales que asuman el decir, como si en alguna medida el lenguaje mismo fuera ya incapaz de responder ante la violencia: «Still, isn't language produced by violence merely language that justifies violence?», se pregunta McClennen (2004, p. 68).

El tono de suposición de la voz que describe la escena -voz que, a su vez, emprende la corrección a posteriori sugerida por el título del poema- desdibuja la contradicción fundamental del lenguaje -aquella entre la afirmación y la negación- y le resta aún más fuerza a la palabra frente a la violencia, como si, de alguna manera, la incerteza que se infiere de los adverbios derivara en cierta equivalencia de la oposición. El pasado de las dos primeras estrofas contrasta con el presente de las últimas tres, que, como se indicó, operan como resolución, como consecuencia: la equivocación de la palabra -cuya consumación se constata en el tiempo del «dijo»- deriva en la confección -cual sastre- de un ataúd a la medida, en medio de una ciudad militarizada. El contraste, como lo advierte Jorge Mario Mejía, también estaría dado por la configuración visual de los versos: «Los versos horizontales del poema hablan de lo que pasa abiertamente en la superficie; los verticales, de lo que ocurre en sus "huecos"» (2013, p. 270). Como se percibe en buena parte de la producción poética analizada, «Fe de erratas» elude también la mención directa al acontecimiento del daño y, por el contrario, este queda sugerido en las imágenes finales. La atención queda puesta entonces en la destrucción de la que es víctima la palabra misma.

El valor ambiguo de la respuesta entre el «sí»y el «no» durante el interrogatorio que acompaña la tortura aparece también tematizado en el poema «Le preguntaron si los había visto pasar», de Horacio Benavides. Sin embargo, la ambigüedad no se configura en este caso por la equivalencia entre la afirmación y la negación sino por la revelación de un enunciado que aparece como falso pero que, de acuerdo con las lógicas del conflicto armado, bien podría adecuarse a los hechos:

(I) LE PREGUNTARON si los había visto pasar y ella les dijo que no

(II) y los había visto porque por aquí pasaban los unos y los otros

(III) Entonces la amarraron le cortaron las manos y los pies y la abandonaron en la orilla del camino

(IV) Lloró y se quejó mientras la sangre se le iba y nadie pudo auxiliarla

(V) $\quad \mathrm{Al}$ fin se quedó en silencio y su silencio grita ahora en esta montaña

(BENAVIDES, 2014) 
Es en los versos 4 y 5 donde se abre la mencionada ambigüedad; específicamente, en la indeterminación de «los unos y los otros», que se suma al plural no determinado que lleva a cabo las acciones de interrogar y de torturar. Quien responde se encuentra justamente en el entre que se abre entre esos unos y esos otros, pues, como reconoce el $\mathrm{CNMH}$, «[1]os actores armados atacan a la población civil como parte de sus estrategias para obligarla a transferir o a mantener sus lealtades y a servir como proveedora de recursos» $(2013$, p. 37). La negativa de la interrogada frente a la pregunta y la aclaración de la voz lírica de que «y los había visto / porque por aquí pasaban /los unos y los otros» evoca justamente la obligada cercanía logística de una mujer cuya palabra se emitirá siempre desde una encrucijada, desde una condena, desde una imposibilidad. A partir del verso 6, el poema abandona el problema verbal de la tortura para centrarse en el daño físico del que es objeto el cuerpo. Sin embargo, los llantos, los quejidos y el silencio final en el verso 11 evidencian la condición del dolor físico como espacio no solo de resistencia frente al lenguaje sino de destrucción del lenguaje (SCARRY, 1987, p. 4).

\subsubsection{La poesía silenciada}

En Colombia, uno de los sectores que más ha padecido el fenómeno particular de la violencia contra la palabra ha sido el del periodismo, silenciamiento que, de acuerdo con el $\mathrm{CNMH}$, deriva en el rompimiento del «tejido comunicativo de comunidades que muchas veces quedan en el desamparo informativo o, lo que es peor, en las interpretaciones únicas» (CNMH, 2015, p. 21). No obstante, dicho acallamiento también ha recaído sobre la poesía; más allá del abordaje temático de ciertos poemas alrededor de esta práctica, los poetas mismos han sido censurados, amenazados, obligados a callar e incluso asesinados por los actores del conflicto armado. Uno de estos casos es nombrado en el poema «Segovia», de María Mercedes Carranza, que evoca el asesinato del poeta y periodista Julio Daniel Chaparro en el municipio de Segovia (Antioquia), en 1991:

\section{Canto 9}

\section{Segovia}

$$
\begin{aligned}
& \text { Los versos } \\
& \text { de Julio Daniel } \\
& \text { son la risa } \\
& \text { del Gato de Cheshire } \\
& \text { en el aire de Segovia. }
\end{aligned}
$$

(CARRANZA, 2014, p. 141)

Se trata, tal vez, del único de los cantos del poemario de Carranza que, a pesar de evocar la realidad de una experiencia del daño, instala la voz de aquel a quien le fue despojada por la violencia. Al silencio inicial que inaugura el poema, señalado por el espacio prelingüístico, se le oponen «Los versos» -la voz, la palabra- del poeta que, como aquella sonrisa del Gato de Cheshire, tiene la facultad de aparecer y permanecer aun sin el cuerpo. La referencia a la «risa», en lugar de la sonrisa característica del gato, evoca más la presencia acústica que la imagen visual, preeminentemente muda; en este sentido, el poema invierte de manera directa el silencio 
impuesto y sitúa en su lugar el sonido vital de la risa, una risa que se establece como uno de los pocos mecanismos de posibilidad de recuperación del lenguaje tras la pérdida (HEUER, 2017, p. 316). De alguna manera, es como si el poema de Carranza atendiera a los versos que el propio Chaparro dejó escritos en un poema de 1986: «si una noche cualquiera me encuentran muerto en una calle / y ven mi boca repleta de insectos rabiosos / trabajando en mi lengua / no me sufran [...] piensen en mí y recuérdenme cantando» (en CADAVID, 2012, p. 69 - 70).

Al caso de Chaparro se suma el de los poetas norte-santandereanos Edwin López, Gerson Gallardo y Tirso Vélez, asesinados por grupos paramilitares en Cúcuta en 2003, en hechos distintos. En su ensayo crítico sobre la antología Palabras como cuerpos, editada por Saúl Gómez Mantilla en 2013, Angélica Hoyos dedica el análisis a algunos de los poemas de estos autores, de los que afirma que ejercían su derecho a decir a través de la poesía, «ejercicio que finalmente los conduciría a su propia muerte en un contexto de guerra que permitió que la palabra poética se silenciara a través del asesinato». De hecho, señala Hoyos que incluso el contenido del poema "Colombia un sueño de paz», de Tirso Vélez, habría incidido en su muerte; un poema que, según Hoyos, fue distribuido en unidades militares y en distintos espacios de la ciudad y que clama por la conciliación y el fin de la violencia (2016, pp. 47 - 48).

La idea de una palabra poética silenciada se ha presentado también en el campo de la poesía indígena. De acuerdo con Miguel Rocha, si bien departamentos como el Cauca o el Huila han sido considerablemente golpeados por el conflicto armado, dicho fenómeno no ha sido una constante en las creaciones de estos autores: de un lado, algunos poetas afirman que se trata de una guerra que no les pertenece; de otro:

[...] durante las últimas dos décadas, con el recrudecimiento del conflicto armado en Colombia, denunciar en nombre propio a los señores de la guerra implica posibles retaliaciones (secuestro, asesinato, persecución). Cuando se trata de creaciones de carácter colectivo, como el videodocumental, en algunos casos disminuyen las posibilidades de un señalamiento personalizado, aunque también los realizadores audiovisuales indígenas reciben amenazas (ROCHA, 2018, p. 122).

Claramente, el silenciamiento de las expresiones indígenas no ha sido un fenómeno exclusivo del conflicto armado colombiano sino una constante desde la conquista y la colonia. A la violencia directa ejercida contra las poblaciones se suma el desplazamiento de las lenguas y expresiones nativas: "[d]esconocer es lo mismo que traicionar la pluralidad de la existencia. Quienes hablan de paz olvidan que los gobiernos han adoptado una lengua europea y no una lengua nativa como lengua oficial. Aceptaron la continuación de un modelo colonialista [...]» (VIVAS, 2015, p. 21). No solo la poesía indígena ha padecido este tipo de acallamiento; son muchas las comunidades y expresiones poéticas que han sido desconocidas por las distintas instancias de reconocimiento o de legitimación literaria, en medio de la lógica excluyente de la tradición colombiana que ha posicionado una visión limitada de lo que debe entenderse por poesía.

\subsection{La palabra imposible}

Al silencio derivado de la imposibilidad de la palabra se le denomina mutismo, en la tipología de Le Breton (2016), y enmudecimiento, en la de Reyes (2016). Thiebaut (2016), por su 
parte, lo incluye entre las formas del callar -focalizadas en quien sufre el daño-, específicamente en la idea de «no poder hablar». De una u otra manera, se trata de la incapacidad del lenguaje para expresar o dar cuenta de la experiencia del daño. Además del mutismo anotado por Walter Benjamin a propósito de los soldados que regresaban del campo de batalla durante la Primera Guerra Mundial (2010, p. 60), la experiencia de Auschwitz y de los campos de concentración en la Segunda Guerra Mundial ha sido entendida a través del silencio como una especie de expresión del fracaso del logos, «de la quiebra de la palabra como razón y gesto humanizador» (FERNÁNDEZ, 2006, p. 1) o asumida como la experiencia donde «imperó lo indecible» (FORSTER, 1997, p. 66). Contrariamente, para Giorgio Agamben, esta idea de «lo indecible» o de lo «incomprensible», con respecto a Auschwitz, opera como una especie de mistificación, como «adorarle en silencio, como se hace con un dios [...] contribuir a su gloria» (2009, p. 32). En este sentido, la poesía se ubicaría entre esta tensión entre el decir y el callar, en donde, más allá de transmitir un contenido, el poema mismo constata las limitaciones de la palabra.

Fueron, justamente, los autores de la literatura del Holocausto los que se destacaron por evidenciar los límites del lenguaje ante la experiencia del daño, y lo hicieron a partir del reconocimiento de que no existía tradición literaria alguna que contara con los medios expresivos disponibles para dar cuenta del horror (REINA, 2009, p. 10); entre estos se encontraban poetas y narradores como Paul Celan, Nelly Sachs, Elie Wiesel e Imre Kertész. De hecho, al describir los motivos recurrentes en la obra de estas voces, José Luis Reina resalta el enmudecimiento como una de las características más relevantes $\left(2009\right.$, p. 10) ${ }^{11}$. Si bien la lucha -la desconfianza- con respecto al lenguaje es una condición inherente a la palabra poética, la ruptura radical de las formas de la lengua no ha sido una constante en la poesía que se ha aproximado a la violencia en Colombia. Las limitaciones de la palabra se han presentado, más bien, como objeto de reflexiones explícitas en los poemas; tal es el caso de la última parte del poemario Sucia luz (2018), de Luis Arturo Restrepo -poemas como "Conjuro», "Juego de espejos», «Infancia», «Camino», «Intención», «Atrevimiento», «La cita», «Compasión», «Cotidiano», «Regla», «Fracaso» y «Esperanza» asumen enteramente la tematización de la difícil relación con la palabra-, y de poemas como «La palabra ha muerto» y «Variable», de los poemarios El sol y la carne (2015) y Arde Babel (2017), respectivamente, de Camila Charry Noriega. Si bien ninguno de estos poemas alude de manera explícita a la experiencia del daño, se encuentran en poemarios donde dicho tema es una constante.

Desde una perspectiva más narrativa que reflexiva, uno de los poemas que con mayor claridad aborda la imposibilidad de la palabra es "Nos recogieron en la plaza», de Horacio Benavides, donde el hablante reconoce que el relato de la experiencia ha llegado a un punto en el que no se puede avanzar más:

(I)

NOS RECOGIERON en la plaza

nos apretujaron en camiones,

las bocas de los fusiles sobre nuestras cabezas

(II) Pensé que debía ser un error

y que volvería a abrazarte
(1)

\footnotetext{
${ }^{11} \mathrm{Al}$ enmudecimiento Reina agrega: «represión del sentimiento de la vida por una constante conciencia de la muerte, desintegración de las expectativas normales de la realidad y perversión de la razón, enmudecimiento, superación violenta de la infancia y del crimen contra esta [...], embrutecimiento del hombre, refugio en el delirio, destrucción del sentido del tiempo" (2009, p. 10).
} 
(III) Un escalofrío me subía por la espalda

y se me encalambraba en el cuello

Pasamos por estaciones de policía

pasamos por retenes

y clamamos

pero nadie nos oyó

(IV) El terror hacía imposible todo consuelo

(V) Me encomendé al Milagroso

recé lo que recordaba

se me heló la sangre al imaginar lo que vendría

(VI) Lo que vino no te lo puedo contar, madre

(BENAVIDES, 2014)

El poema se construye a partir del relato que hace un hablante a un tú, la madre. El tiempo verbal -pretérito- lo inscribe como una especie de testimonio de la experiencia, en la que se evidencian dos rupturas: de un lado, la del vínculo afectivo, marcada por el contraste entre el pretérito del «pensé» del verso 4 y el condicional del «volvería a abrazarte» del verso 5, que sentencia la ilusión y quiebra el reencuentro; de otro, la ruptura del relato mismo en el verso 16, donde el final del poema coincide con el reconocimiento del hablante de la imposibilidad de continuar relatando. Dicha imposibilidad está, a su vez, construida sobre la base de una indeterminación, de un silencio, que le otorga la carga de ambigüedad al poema: ¿se suspende el relato por la ausencia de palabras frente al horror de «lo que vino» o se suspende por la ausencia misma del hablante con respecto al espacio del tú? Si se atiende a los versos 4 y 5 se trataría de un discurso construido desde la ausencia, desde el no-lugar de la muerte: el relato se interrumpe en el momento en que la vida del hablante se interrumpe; si se atiende únicamente al verso 16 , se trataría del enmudecimiento del hablante. De ahí que sea en la coexistencia de estos dos momentos -los dos momentos en que aparece el tú - en donde recae la tensión irresuelta del texto.

Tanto lo imaginado del verso 15 como lo callado del verso 16 evidencian que el silencio recae en ese lo, pronombre que indica aquello que el discurso omite, que nombra sin nombrar. Se trata justamente del lugar límite que ocupa la palabra poética frente al daño: «the poetry of torture recognizes the impossibility of describing torture at the same time that it registers the need to bear witness» (McCLENNEN, 2004, p. 68). Más que dar cuenta de un qué, se plasma la necesidad de dar cuenta de que hubo un qué que no puede ser traído al lenguaje. Si dicho qué, dicho contenido, debe su inexpresibilidad a su referencia al dolor, lo evocado alberga también una incompartibilidad - «unshareability»-, en tanto el dolor es resistente al lenguaje (SCARRY, 1987, p. 4). En este sentido, esta incompartibilidad del dolor, manifiesta en la reticencia del hablante, entrañaría también un silencio de protección del interlocutor, de la madre, en este caso.

Además del silencio de la comentada indeterminación del poema, de la imposibilidad de la palabra o de la mencionada protección del interlocutor, en «Nos recogieron en la plaza» es posible rastrear otras expresiones del silencio en relación con el daño; entre estas, la imposición del silencio, que atraviesa la experiencia completa del hablante, y la palabra ignorada de los versos 10 y 11 -«y clamamos / pero nadie nos oyó»-, manifestación que será objeto de reflexión 
en el siguiente apartado. Asimismo, en lo callado reside el núcleo del acontecimiento violento, donde es dable escuchar el grito de las víctimas, tal como lo menciona Mèlich en el enunciado tomado como epígrafe de esta reflexión (2001, p. 27).

\subsection{La palabra ignorada}

De acuerdo con los esfuerzos de desambiguación del silencio y en relación con la figura que desatiende la palabra del otro, es posible entender la palabra ignorada en un doble plano. De un lado, el no dejar oír -ensordecimiento- y el no escuchar como prácticas incluidas en el repertorio de acciones u omisiones de quien causa el daño (THIEBAUT, 2017, p. 232). De otro, estarían «el silencio de los espectadores», en la tipología de Thiebaut (2017, p. 239), o la indiferencia, en la formulación de Le Breton (2016, pp. 76-77), relacionados con el silencio que recae en los terceros. A este segundo plano se refería Nelly Sachs en un poema que cuestionaba, justamente, la posición -cómplice- de quienes optaron por mirar hacia otro lado durante el Holocausto nazi: «Vosotros espectadores, / que no alzasteis ninguna mano de asesino, pero que no agitasteis el polvo de vuestro / anhelo, / que os detuvisteis allí donde se transfigura / en luz» (2009, p. 70).

En la poesía de la violencia en Colombia pueden encontrarse tematizadas las dos posibilidades: tanto la violencia que inflige el victimario al rehusarse a escuchar a la víctima como el estado de adormecimiento e indiferencia de la sociedad -o del Estado- frente al daño, desatención que, por lo general, deriva en una revictimización. Se trata de una palabra que no encuentra ni la resonancia ni las condiciones para ser asimilada; una palabra que se enfrenta al silencio, no de la ausencia, sino de la falta de «disposición a la escucha» (ARFUCH, 2013, p. 15). Si bien en Conversación a oscuras (2014), de Horacio Benavides, es frecuente el motivo de la imposibilidad del diálogo -bien sea por la ausencia del interlocutor o por la ausencia misma del hablante del mundo de los vivos-, el poema «Les mostró las manos callosas», aborda específicamente la no escucha del victimario. De otro lado, como se verá más adelante, la apertura de la pregunta «ante quién», en el poema "De la muchacha asesinada», de Pedro Arturo Estrada, plantea la ausencia de cualquier tipo de interlocutor o responsable al que se le pueda exigir respuesta frente al daño.

(I) LES MOSTRÓ las manos callosas pero no lo escucharon

(II) Les mostró los arpones los peces la carne de animales muertos

(III) Le gritaron que era auxiliador de los otros que lo habían visto venderles cocos

(IV) Les señaló a sus hijos pequeños

a su mujer en cinta

pero no lo escucharon

(BENAVIDES, 2014)

Construido desde la voz de un tercero que describe la escena, el poema se acerca al 
mencionado motivo de la víctima que se encuentra en la encrucijada entre los unos y los otros. Se trata entonces de un él que responde a los unos por haber «auxiliado»-la venta de unos cocos se asume como «auxilio» en la versión de esos unos- a los otros. Pero el sujeto sobre el que está focalizada la acción no ofrece versión alguna, no es su palabra la que no es escuchada: son sus propias acciones las que aparecen en los versos 1, 3 y 7 del poema. La palabra, que podría ser puesta en duda, es aquí reemplazada por la mostración de los indicios -las manos callosas, los arpones, los peces, la carne de animales muertos- y de los motivos -su familia-, que constata la práctica de un oficio que no debe asumirse como auxilio para esos otros. Aun así, no lo escucharon. Para Byung-Chul Han, es la escucha misma la que antecede al habla, la que posibilita, previamente, el diálogo: "Yo ya escucho antes de que el otro hable, o escucho para que el otro hable. La escucha invita al otro a hablar, liberándolo para su alteridad» (2018, p. 114). Pero aquí no hay tal disposición anterior; la versión de esos unos pareciera preceder a la acción misma descrita por el poema: el pretérito anterior del verso 7 - «lo habían visto»antecede a las explicaciones y ha cerrado ya -desde antes de que el intercambio tenga lugar- la posibilidad de cualquier palabra/mostración que apunte en una dirección distinta. El grito de la no escucha, del juicio a priori, se ha impuesto a la evidencia. Y es justamente la no escucha del último verso del poema la que queda resonando; el poema termina entonces con un doble silencio: aquel con el que se encuentra el sujeto no escuchado, y la apertura a la que se enfrenta el lector, que tensiona la indeterminación de un final abierto, con la certeza de lo que tradicionalmente ha ocurrido cuando los victimarios desatienden las razones de las víctimas.

Como se mencionó arriba, en el caso de «De la muchacha asesinada», si bien la voz hablante se encuentra en el no-lugar de la muerte -voz que, de entrada, no sería escuchada-, el énfasis temático recae justamente en la ausencia de instancias ante las cuales pedir respuesta por el daño. Incluso, la construcción del título mismo, a partir de un sintagma preposicional sin el sustantivo al cual se enlaza, podría leerse como una palabra ya silenciada:

\section{De la muchacha asesinada}

(I) Ante quién,

por mis manos y pies hechos polvo,

mi rostro en su primera lozanía, calcinado,

por mis pechos cercenados esa noche,

clamaré restitución.

(II) Ante quién,

por los días más bellos arrojados al fuego,

por la risa de la mañana, aniquilada,

la fuerza de mi sangre sembrada entre piedras,

tasaré la pérdida.

(III) Ante quién,

del amor destruido, los sueños bajo tierra,

la belleza reducida a un montón de vísceras

abiertas, el deseo mutilado;

del grito y el sollozo solo oídos

por las potencias indiferentes,

pediré respuesta.

(IV) Ante quién, 
por la palabra todavía crédula o apenas ingenua

de la vida y el espanto que la ahogó,

obtendré explicación.

(ESTRADA, 2006, p. 35 - 36)

Con el paralelismo conformado por el primero y el último verso de cada estrofa se construye el campo semántico anotado, relacionado con la imposibilidad de interpelación de la víctima. El enunciado «ante quién», más que interrogar -ausencia de signos de interrogaciónafirma reiteradamente la ausencia de interlocutor o, mejor, de un responsable que se encargue de atender al verbo que cierra cada una de las estrofas: clamar restitución, tasar la pérdida, pedir respuesta, obtener explicación. Se trata de verbos relacionados con la demanda de la víctima y con los procesos de elaboración del daño -ante el victimario o ante las terceras figuras- que quedan claramente pendientes o irresueltos; abarcan una especie de dimensión pública del daño en un reclamo silenciado por la indiferencia. De hecho, esta aparece explícitamente en los versos 15 y 16 como recipiente indiferente -sordo- de gritos y sollozos, que ignorará el reclamo.

La dimensión más privada o íntima del daño aparece en los versos intermedios de cada estrofa. En la primera, se alude específicamente al daño físico del que fue víctima el cuerpo de la muchacha que habla en el poema. En las estrofas II, III y IV aparecen otros de sus rasgos puestos en relación con imágenes de un futuro que no fue, de un porvenir frustrado. Tanto en lo relacionado con la corporalidad como en lo que tiene que ver con la risa, la fuerza, el deseo en pocas palabras, la actitud vital-, los versos están construidos a partir de la exaltación del contraste, mecanismo que, claramente, acentúa el efecto del daño causado; es decir, la oscilación entre vida y muerte se encuentra, prácticamente, en cada uno de los versos, repetición que realza la pérdida.

\section{Reflexiones finales}

No existe un significado preciso y estable del silencio; se trata, tal vez, del más ambiguo de los signos (CASTILLA DEL PINO, 1992, p. 83). Sí hay, no obstante, significación en el hacer silencio; es decir, en el silencio como práctica. En este sentido, es posible delimitar dichas posibilidades de significación en el contexto socio-cultural y en las situaciones comunicativas que rodean la experiencia del daño. En tanto lenguaje íntimamente vinculado con el silencio capaz de forzar los límites del lenguaje discursivo y de acercarse a la expresión misma de lo inexpresable-, la palabra poética deviene espacio de reflexión temática y de aparición expresiva de las formas del silencio. Y así lo ha asumido la poesía más reciente que se ha aproximado al fenómeno de la violencia en Colombia.

La necesidad de indagar en la paradójica situación en la que el poeta escribe sobre o escribe desde el silencio que se relaciona con el daño no es otra que la de reconocer en el poema la responsabilidad de tomar distancia del mutismo cómplice de la barbarie, del ocultamiento y del olvido. Hablar del silencio del daño es entonces -siguiendo a Agamben (2009, p. 32)contribuir a la des-mistificación del horror. Pero es a la vez reconocer que no todo silencio es negativo, que no todo silencio es destrucción: que reivindicar y dirigir la conciencia hacia el silencio -como lo hacen poetas y poemas- es, al mismo tiempo, restablecer el valor de la palabra. 


\section{Referencias}

AGAMBEN, G. Lo que queda de Auschwitz: el archivo y el testigo. Homo sacer III. Valencia: Pretextos, 2009.

ARANGO, J. M. Poesía. Bogotá: Instituto Caro y Cuervo, 2015.

ARFUCH, L. Memoria y autobiografía: exploraciones en los límites. Buenos Aires: Fondo de Cultura Económica, 2013.

BENAVIDES, H. Conversación a oscuras. Medellín: Frailejón editores, 2014.

BENJAMIN, W. El narrador. Santiago de Chile: ediciones/metales pesados, 2010.

CADAVID, J. (ed.). República del viento: antología de poetas colombianos nacidos en los años sesenta. Medellín: Editorial Universidad de Antioquia, 2012.

CARRANZA, M. M. Su poesía. Tomo I. Bogotá: Instituto Caro y Cuervo, 2014.

CASTILLA DEL PINO, C. Introducción. En: El silencio: compilación de Carlos Castilla del Pino, pp.11-13. Madrid: Alianza Editorial, 1992.

CHARRY NORIEGA, C. El sol y la carne. Madrid: Ediciones Torremozas, 2015.

CHARRY NORIEGA, C. Arde Babel. Bogotá: Universidad Externado de Colombia, 2017.

CNMH. ¡Basta ya!: Colombia: Memorias de guerra y dignidad. Bogotá: Imprenta Nacional, 2013.

CNMH. La palabra y el silencio: la violencia contra periodistas en Colombia (1977 - 2015). Bogotá: CNMH, 2015.

COTE, A. Puerto calcinado. Bogotá: Universidad Externado de Colombia, 2003.

ESTRADA, P. A. Oscura edad y otros poemas. Bogotá: Universidad Nacional de Colombia, 2006.

FERNÁNDEZ, J. A. Pensar desde el silencio: representación y discurso después de Auschwitz. A Parte Rei: revista de filosofía, número 43, pp. 1 - 7, 2006.

FIERRO, A. La conducta del silencio. En: CASTILLA DEL PINO, C. El silencio: compilación de Carlos Castilla del Pino. Madrid: Alianza Editorial, 1992.

FORSTER, R. Hurbinek: la palabra inaudible o el decir después de Auschwitz. Nombres: revista de filosofía, número 10, pp. 65-76, 1997.

GALEANO, J. C. Polen y escopetas: la poesía de la Violencia en Colombia. Bogotá: Editorial Universidad Nacional, 1997.

GALTUNG, J. Contribución específica de la irenología al estudio de la violencia: tipologías. En: VV.AA. La violencia y sus causas. París: Unesco, 1981.

GARCÍA MÁRQUEZ, G. Dos o tres cosas sobre «La novela de la violencia». Disponible en $<$ https://www.revistaarcadia.com/agenda/articulo/dos-tres-cosas-sobre-la-novela-de-laviolencia/36312>, 2014. Acceso en: 7 de abril 2020.

HAN, B. C. La expulsión de lo distinto. Barcelona: Herder, 2018.

HEUER, W. Volver a hablar tras la muerte del lenguaje: sobre los esfuerzos de aprender a 
hablar y la facilidad de perder el lenguaje de nuevo. En: DE GAMBOA, C; URIBE, M. V. Los silencios de la guerra. Bogotá: Editorial Universidad del Rosario, 2017.

HOYOS, A. Memoria, duelo y resistencia en Palabras como cuerpos de Saúl Gómez Mantilla. Estudios de literatura colombiana, Medellín, número 39, pp. 45-59, 2016.

JARAMILLO ESCOBAR, J. Poemas principales. Valencia: Pre-textos, 2000.

LAÍN ENTRALGO, P. Antropología de la esperanza. Barcelona: Punto Omega, 1978.

LE BRETON, D. El silencio: aproximaciones. Madrid: Ediciones Sequitur, 2016.

LUQUE, H. (ed.). Tambor en la sombra: poesía colombiana del siglo XX. San Luis de Potosí: Editorial Ponciano Arriaga, 1996.

McCLENNEN, S. Poetry and Torture. World Literature Today, september - december. 2004, pp. 68-70.

MÈLICH, J. C. La ausencia del testimonio: ética y pedagogía en los relatos del Holocausto. Barcelona: Anthropos Editorial, 2001.

NOUSS, A. Habla sin voz. En: DERRIDA, J.; SUSSANA, G.; NOUSS, A. Decir el acontecimiento, ies posible? Madrid: Arena Libros.

ORTIZ, O. Diario de los seres anónimos. Granada: La Mirada Malva, 2015.

PARDO, H. Los días derrotados. Calarcá: Cuadernos Negros Editorial, 2016.

PARDO, H. Reino de peregrinaciones. Cúcuta: Gobernación de Norte de Santander, 2017.

REINA, J. L. Prólogo: viaje a la transparencia. Sobre la obra de Nelly Sachs. En: SACHS, N. Viaje a la transparencia: obra poética completa. Madrid: Editorial Trotta, 2009.

RESTREPO, E. A. (ed.). Entre el miedo y el mal: el género negro en la poesía colombiana. Medellín: Hilo de plata Editores, 2014.

RESTREPO, L. A. Sucia luz. Medellín: Sílaba Editores, 2018.

REYES, R. Enmudecer, acallar, guardar: violencia y silencio en el México contemporáneo. En: DE GAMBOA, C; URIBE, M. V. Los silencios de la guerra. Bogotá: Editorial Universidad del Rosario, 2017.

RICOEUR, P. Del texto a la acción: ensayos de hermenéutica II. México D.F.: Fondo de Cultura Económica, 2010.

ROCHA, M. Mingas de la palabra: Textualidades oralitegráficas y visiones de cabeza en las oraliteraturas y literaturas indígenas contemporáneas. Bogotá: Universidad de los Andes, Ediciones Uniandes: Pontificia Universidad Javeriana, 2018.

SACHS, N. Viaje a la transparencia: obra poética completa. Madrid: Editorial Trotta, 2009.

SCARRY, E. The Body in Pain: The Making and Unmaking of the World. New York: Oxford University Press, 1987.

STEINER, G. Lenguaje y silencio: ensayos sobre la literatura, el lenguaje y lo inhumano. Barcelona: Editorial Gedisa, 2013.

THIEBAUT, C. Daño y silencio. En: DE GAMBOA, C; URIBE, M. V. Los silencios de la guerra. Bogotá: Editorial Universidad del Rosario, 2017. 
THIEBAUT, C. La experiencia del daño y su resolución: una indagación conceptual. En: GÓMEZ RAMOS, A.; SÁNCHEZ MUÑOZ, C. Confrontando el mal: ensayos sobre violencia, memoria y democracia. Madrid: Plaza y Valdés Editores.

VANEGAS, B. El canto de las moscas y la predicación sobre la violencia ocultada. Escritos: Revista del Centro de Ciencias del Lenguaje, Puebla, número 37-38, enero-diciembre, 2008, pp. 25-40.

VIVAS, S. Komuya uai: poética ancestral contemporánea. Medellín: Sílaba Editores, 2015.

Recebido em: 13/05/2020

Aceito em: 02/07/2020 